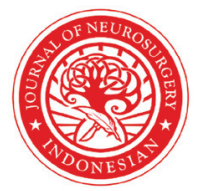

Indonesian Journal of Neurosurgery

\section{The role of acute traumatic focal lesion on head CT scan in predicting outcome of mild traumatic brain injury patients}

\author{
Nyoman Golden ${ }^{1 *}$, Putu Eka Mardhika', Wayan Niryana', \\ Tjokorda GB Mahadewa', Sri Maliawan'
}

${ }^{1}$ Neurosurgery Division, Department of Surgery, Faculty of Medicine, Universitas Udayana, Sanglah General Hospital, Bali, Indonesia.

\footnotetext{
*Corresponding to:

Nyoman Golden; Neurosurgery Division, Department of Surgery, Faculty of Medicine, Universitas Udayana, Sanglah General Hospital, Bali, Indonesia; nyoman_golden@yahoo.com
}

Received: 2020-10-11

Accepted: 2021-07-20

Published: 2021-08-01

\section{ABSTRACT}

Background: There is a controversy regarding the examination of head CT scan in Mild Traumatic Brain Injury (mTBI) patients with a GCS score of 15 . We proposed that the presence of intracranial lesion in head CT scan is more important in predicting outcome of $\mathrm{mTBI}$ patients regardless of GCS score. This study aimed to determine the role of intracranial lesions in mTBI patients in predicting outcome of mTBI patients.

Methods: This was a prospective cohort study conducted at Sanglah Hospital Denpasar Bali. Samples of patients with a diagnosis of mTBI with GCS score 14 - 15 were recruited consecutively. Data were calculated and analyzed statistically.

Results: The presence of focal lesions on head CT scan had an adjusted RR of 3.75 in determining surgery after controlling the role of GCS $(<0.001)$. The presence of focal lesions on head $\mathrm{CT}$ scan had an adjusted RR of 13.9 in predicting poor outcome after controlling the role of $\mathrm{GCS}(\mathrm{p}<0.012)$.

Conclusions: The presence of acute focal lesions on head CT scan has been shown to be a significant factor affecting the outcome and the need for surgery in $\mathrm{mTBI}$ patients. GCS is not proven to be a factor affecting the outcome and the need for surgery in mTBI patients.

Keywords: focal intracranial lesion, glasgow coma scale, glasgow outcome scale extended, head ct scan, mild traumatic brain injury

Cite This Article: Golden, N., Mardhika, P.E., Niryana, W., Mahadewa, T.G.B., Maliawan, A. 2021. The role of acute traumatic focal lesion on head CT scan in predicting outcome of mild traumatic brain injury patients. Indonesian Journal of Neurosurgery 4(2): 64-68. D0I: 10.15562/ijn.v4i1.150

\section{INTRODUCTION}

Traumatic brain injury (TBI) is a major cause of death and disability in adults under 45 years old. ${ }^{1}$ Based on the Glasgow Coma Scale (GCS), TBI is divided into three classifications, which are mild (GCS 13 - 15), moderate (GCS 9 - 12), and severe TBI (GCS 3 - 8). Some authors define Mild Traumatic Brain Injury (mTBI) as a GCS score of $14-15$. About $80 \%$ of all head injured patients are mTBI. ${ }^{1,3}$ At our hospital, the average incidence of head injury is above 2,000 cases per year, and more than $70 \%$ are dominated by $\mathrm{mTBI}^{4}$ GCS score in mTBI does not fully reflect the degree of brain damage. ${ }^{5,6}$ For example, patients who admitted with GCS score of 15 may have traumatic intracranial lesions that develop into a coma or even death.

Patients with GCS score 13 and 14 are certainly indicated for CT scans., ${ }^{2,6-9}$ However, indication for CT scan in patients with GCS score 15 is still controversial. Consequently, researchers have used various criteria to perform CT scans of patients with GCS 15, such as Miller's criteria, New Orleans Criteria, Canadian CT Head Rule, and CT in Head Injury Patient (CHIP)., ${ }^{2,10,11}$ This controversy is caused by the desire to cut hospital costs while being able to detect all intracranial lesions in mTBI patients. ${ }^{8,12}$ However, the average cost of mTBI patients who need hospital observation without CT scan is more expensive than those with mTBI with normal CT scans who are discharged immediately. ${ }^{13}$ Therefore, the initial CT scan is a safe strategy for triage management of mTBI to detect the presence of acute focal intracranial lesion. Considering that the presence of intracranial lesions indicate the severity of the head injury, some researchers performed CT scans on all mTBI patients. ${ }^{14}$

Intracranial lesions, need for surgery, and outcomes are varies between range of GCS score 13 and 15 in mTBI patients. ${ }^{15}$ Some researchers report that the lower the GCS score, the greater the chance for intracranial lesions to occur and require surgery. ${ }^{6,7,9,15,16}$ Intracranial lesions and the need for surgery are indicators of injury severity because they are closely related to outcomes. ${ }^{6,7}$ Even patients with GCS score 13 have been shown to have the same incidence of intracranial lesions as moderate traumatic brain injuries. ${ }^{16}$

We consider the need for a combination of GCS score and CT scan to classify mTBI. Some authors consider serious lesions as intracranial lesions that require 
surgery. However, to ensure patient safety, we decided that every traumatic intracranial lesion is a serious condition. It is supported by some researchers that reported enlarging intracranial lesions during observation and eventually require surgery. ${ }^{3}$ Based on this finding, we conducted a study to determine the role of intracranial lesions in mTBI patients in determining the need for surgery and outcome.

\section{METHODS}

This was a prospective cohort study conducted at Sanglah General Hospital Denpasar, Bali. The samples were patients with a diagnosis of mTBI with a GCS score of 14 - 15 who were treated in the surgical ward, who were recruited consecutively. The inclusion criteria were traumatic brain injury patients more than six years old with a GCS score of 14 - 15 who arrived within 12 hours after the accident and agreed to participate in this study. The exclusion criteria were patients with a traumatic brain injury who experienced trauma in other organs that require special care, patients with a history of neurosurgical intervention, those who were under the influence of alcohol or drugs, those with a history of cardiovascular disease or other intracranial pathologies, patients with a history of coagulopathy who consumed blood thinning medication, and those with penetrating traumatic brain injuries. The informed consent was obtained from all patients that were able to sign the informed consent form. In case of patient below 18 years old, we got the consent from their parents.

mTBI was defined as a traumatic brain injury with a GCS score of 14-15, regardless of other symptoms. ${ }^{17}$ GOS extended (GOSE) was measured to determine the outcome in traumatic brain injuries to express prognosis assessed four months after the injury. GOSE was dichotomized into good and poor outcomes. A good outcome was defined as having a GOSE score of $7-8$, while a poor outcome was defined as having a GOSE score of $1-6$. Focal lesion refers to all acute traumatic intracranial lesions such as epidural hematoma $(\mathrm{EDH})$, subdural hematoma $(\mathrm{SDH})$, intraventricular hemorrhage (IVH), intracerebral hemorrhage (ICH), subarachnoid hemorrhage (SAH) and cerebral contusion regardless of their volume. The CT scan results were read by a neurosurgeon and were confirmed by a radiologist. Neurosurgical operation was defined as all craniotomy or craniectomy to correct acute traumatic lesions but not including the installation of intracranial pressure monitors. $^{2}$

Each research subject who met the inclusion criteria received treatment according to Advanced Trauma Life Support and our neurosurgical department protocol. We will perform surgery if traumatic intracranial lesion are present in the head CT scan. The indication to perform surgery are including EDH with volume more than $30 \mathrm{cc}$ and/or midline shift more than $5 \mathrm{~mm}$; SDH with thickness more than $10 \mathrm{~mm}$ and/or midline shift more than $5 \mathrm{~mm}$; ICH with volume more than $20 \mathrm{cc}$ in frontal and temporal lobe, and volume more than $50 \mathrm{cc}$ in parietal and occipital lobe. GOSE evaluation was performed on all study subjects three months after the trauma.

Data were calculated and analyzed statistically. Descriptive statistical analysis was done to describe the characteristics of the data. Bivariate analysis between GCS values and GOSE, and between focal lesions and GOSE were done using the Chi-square analysis. Multivariate analysis

Table 1. Characteristics of sample

\begin{tabular}{lc}
\multicolumn{1}{c}{ Variable } & $\mathbf{n}=\mathbf{3 0 6}$ \\
\hline Age & $31.9 \pm 15.9$ \\
Mean & $6-79$ years \\
Min - Max & \\
Sex & $222(72.8 \%)$ \\
Male & $83(27.2 \%)$ \\
Female & \\
Mechanism of injury & $272(88.89 \%)$ \\
Traffic accident & $34(11.11 \%)$ \\
Non-traffic accident & \\
GCS score & $139(45.42 \%)$ \\
14 & $167(54.58 \%)$ \\
15 & \\
Focal lesion & $171(55.88 \%)$ \\
Present & $135(44.12 \%)$ \\
Absent & \\
Management & $47(15.36 \%)$ \\
Surgery & $259(84.64 \%)$ \\
Conservative &
\end{tabular}

using the Mantel-Haenszel test and Poisson Regression method was done to determine the relationship between GCS and focal lesion to the outcome (GOSE).

\section{RESULTS}

There were 306 samples that met the inclusion criteria. In summary, the characteristic of the samples can be seen in Table 1. that 35 patients $(25.9 \%)$ with focal lesions received surgery, while 12 patients (7\%) without focal lesions received surgical therapy. The relative risk of surgery was 3.7 times higher in focal lesion than without focal lesions. This shows that the CT scan result is a factor that can determine the need for surgery, with p-value $<0.001$.

In Table 3, it can be seen that the prevalence of surgical need between a GCS score 14 and 15 was similar $(15.11 \%$ and $15.57 \%$ respectively), with a $\mathrm{RR}$ of 1 . This difference was not statistically significant, with a p-value of 0.918 ( $>0.05)$. This indicates that GCS could not be used to determine the need for surgery.

As presented in Table 4, 11 patients $(8.2 \%)$ with focal lesions had poor outcomes, whereas only one patient $(0.6 \%)$ without focal lesions had a poor outcome. Patients with focal lesion had
As shown in Table 2, it was found 
risk having poor outcome 13.9 times higher than without focal lesions ( $\mathrm{p}=$ 0.001).

As can be seen in Table 5, in the poor outcome group, six patients (4.32\%) had a GCS score of 14, and six patients (3.59\%) had a GCS of 15 , with a RR of 0.83 ( $\mathrm{p}=$ $0.75)$. There was no significant difference between the two groups.

As displayed in Table 6, the presence of focal lesions on head CT scans proved to play a role in determining surgery with an adjusted RR of 3.75 after controlling the role of GCS $(<0.001)$.

In Table 6, it can be seen that the presence of focal lesions on head CT

Table 2. The relationship between acute focal lesion finding on head CT scan and surgical management

\begin{tabular}{|c|c|c|c|c|c|c|c|c|c|}
\hline \multirow{3}{*}{$\begin{array}{l}\text { Focal } \\
\text { lesion }\end{array}$} & \multicolumn{4}{|c|}{ Therapy } & \multirow{2}{*}{\multicolumn{2}{|c|}{ Total }} & \multirow{3}{*}{$95 \% \mathrm{Cl}$} & \multirow{3}{*}{ P-value } & \multirow{3}{*}{$\mathbf{R R}$} \\
\hline & \multicolumn{2}{|c|}{ Conservative } & \multicolumn{2}{|c|}{ Operation } & & & & & \\
\hline & $\mathbf{n}$ & $\%$ & $\mathbf{n}$ & $\%$ & $\mathbf{n}$ & $\%$ & & & \\
\hline Absent & 159 & 93.06 & 12 & 7.0 & 171 & 55.88 & & & \\
\hline Present & 100 & 74.1 & 35 & 25.9 & 135 & 44.12 & $2.0-6.8$ & $<0.001$ & 3.7 \\
\hline Total & 259 & 84.64 & 47 & 15.36 & 306 & 100 & & & \\
\hline
\end{tabular}

Table 3. The relationship between GCS score and surgical management

\begin{tabular}{|c|c|c|c|c|c|c|c|c|c|}
\hline \multirow{3}{*}{ GCS } & \multicolumn{4}{|c|}{ Therapy } & \multirow{2}{*}{\multicolumn{2}{|c|}{ Total }} & \multirow{3}{*}{$95 \% \mathrm{Cl}$} & \multirow{3}{*}{ P-value } & \multirow{3}{*}{$\mathbf{R} \mathbf{R}$} \\
\hline & \multicolumn{2}{|c|}{ Conservative } & \multicolumn{2}{|c|}{ Operation } & & & & & \\
\hline & $\mathbf{n}$ & $\%$ & $\mathbf{n}$ & $\%$ & $\mathbf{n}$ & $\%$ & & & \\
\hline 14 & 118 & 84.89 & 21 & 15.11 & 139 & 45.42 & & & \\
\hline 15 & 141 & 84.43 & 26 & 15.57 & 167 & 54.58 & $0.6-1.8$ & 0.918 & 1.0 \\
\hline Total & 259 & 84.64 & 47 & 15.36 & 306 & 100 & & & \\
\hline
\end{tabular}

Table 4. The relationship between acute focal lesion finding on head CT scan and outcome

\begin{tabular}{|c|c|c|c|c|c|c|c|c|c|}
\hline \multirow{3}{*}{ Focal lesion } & \multicolumn{4}{|c|}{ Outcome } & \multirow{2}{*}{\multicolumn{2}{|c|}{ Total }} & \multirow{3}{*}{$95 \% \mathrm{Cl}$} & \multirow{3}{*}{ P-value } & \multirow{3}{*}{$\mathbf{R R}$} \\
\hline & \multicolumn{2}{|c|}{ Good } & \multicolumn{2}{|c|}{ Poor } & & & & & \\
\hline & $\mathbf{n}$ & $\%$ & $\mathbf{n}$ & $\%$ & n & $\%$ & & & \\
\hline Absent & 170 & 99.4 & 1 & 0.6 & 171 & 55.9 & & & \\
\hline Present & 124 & 91.8 & 11 & 8.2 & 135 & 44.1 & $1.8-106.6$ & 0.001 & 13.9 \\
\hline Total & 294 & 96 & 12 & 4 & 306 & 100 & & & \\
\hline
\end{tabular}

Table 5. The relationship between GCS score and outcome

\begin{tabular}{|c|c|c|c|c|c|c|c|c|c|}
\hline \multirow{3}{*}{ GCS } & \multicolumn{4}{|c|}{ Outcome } & \multirow{2}{*}{\multicolumn{2}{|c|}{ Jumlah }} & \multirow{3}{*}{$95 \% \mathrm{Cl}$} & \multirow{3}{*}{ P-value } & \multirow{3}{*}{ RR } \\
\hline & \multicolumn{2}{|c|}{ Good } & \multicolumn{2}{|c|}{ Poor } & & & & & \\
\hline & $\mathbf{n}$ & $\%$ & $\mathbf{n}$ & $\%$ & $\mathbf{n}$ & $\%$ & & & \\
\hline 14 & 133 & 95.68 & 6 & 4.32 & 139 & 45.43 & & & \\
\hline 15 & 161 & 96.41 & 6 & 3.59 & 167 & 54.57 & $0.27-2.58$ & 0.75 & 0.83 \\
\hline Total & 294 & 96 & 12 & 4 & 306 & 100 & & & \\
\hline
\end{tabular}

Table 6. Poisson regression analysis of the presence of focal lesions in determining surgical management and outcome

\begin{tabular}{ccccc}
\hline Independent variable & Dependent variable & RR & $\mathbf{9 5 \%} \mathbf{C l}$ & P value \\
\hline $\begin{array}{c}\text { Presence of focal lesion on } \\
\text { head CT scan }\end{array}$ & Surgical management & 3.75 & $1.9-7.2$ & $<0.001$ \\
& Outcome & 13.9 & $1.79-108.3$ & $<0.012$ \\
\hline
\end{tabular}

scans had a strong role in determining the outcome, with an adjusted RR of 13.9 after controlling the role of GCS $(\mathrm{p}<0.012)$.

\section{DISCUSSION}

mTBI is a common problem found in emergency departments. Although the incidence is low, patients with a GCS score of 15 can experience acute deterioration with extensive bleeding, which can be followed by death. ${ }^{18}$ The focus of mTBI management is early detection of intracranial lesions, followed by surgery to save the life of the patient. ${ }^{11,22}$ The management of traumatic brain injury is very important for early detection of intracranial lesions and early decision to perform surgery before complications from these lesions occur. ${ }^{2}$

In this study, the incidence of acute intracranial lesions was 171 cases $(55.88 \%)$, and 47 cases $(15.36 \%)$ required surgery. This is slightly different from other study where acute intracranial lesions were only found in $13.2 \%$ of cases, and as many as $3.6 \%$ required surgery. ${ }^{2}$ Hsiang et al. ${ }^{7}$ reported a $17 \%$ incidence of abnormal CT scans, and the need for surgery was $3.2 \%$.

This study found that men had more mTBI than women $(72.8 \%$ and $28.2 \%$ respectively). Other descriptive data states that men experience more mTBI, which is equal to $65.1 \%^{2}, 65 \%^{12}, 76 \%^{3}$, amounting to $52 \% .{ }^{19}$ The mean age of patients with mTBI in other study was $32.83 \pm 18.20$ years. ${ }^{2}$ This is similar to the mean age of patients who experienced mTBI in this study $(31.9 \pm 15.9$ years $)$. It was found that most patients $(88.89 \%)$ in this study experienced mTBI as a result of traffic accidents. Motor vehicle accidents are a common cause of mTBI. This is due to high mobility among the productive age group and the low awareness of road safety, in addition to the incorrect initial management and late referrals. Cullota et $a l .{ }^{15}$ reported that the degree of brain damage and the possible need for surgery significantly increases with the decline of the GCS score from 15 to 13. In this study, we found that GCS did not have an important role in determining the need for surgery and patient outcomes in $\mathrm{mTBI}$. The results of the bivariate analysis showed that patients with a GCS score of 14 had an unfavorable outcome, almost 
the same as patients with a GCS score of 15.

Focal traumatic lesions in this study were the factors that determine the outcome of mTBI patients. It can be concluded that patients with focal traumatic lesions have a relative risk of 13.9 times having poor outcome than those without focal lesions. Focal lesion had a strong role in the outcome, with an adjusted RR of 13.9 after controlling for the role of GCS. The assessment of outcome showed us that mTBI with focal lesion tends to have more severe neurologic sequelae than those without focal lesion regardless of GCS score on admission. It indicates heterogeneity of pathophysiology among patients with GCS ranges from 13 to 15 . The main problem of mTBI is unable to detect the acute focal lesions early when the use of CT scans is limited. On the other hand, the presence of acute intracranial lesions reflects the seriousness of the injury, which plays a role in the need for surgery and outcome. ${ }^{6,11}$ This study showed the central role of abnormal CT scans in the treatment of patients with mTBI, especially in observations or decisions to discharge the patients.

Regarding the risk of abnormal CT scans, some researchers divided mTBI into high risk and low risk (without risk). ${ }^{7,9,15,20,21}$ From the literature review, mTBI with GCS score of $13-14$ and linear fractures are categorized as mTBI with high risk, whereas a GCS score of 15 without focal lesions is considered as mTBI with low risk or no risk. Although mTBI with a GCS score of 15 is categorized as low-risk MTBI, some cases reported acute deterioration. ${ }^{18}$ Turedi et al. ${ }^{9}$ reported a $6 \%$ incidence $\mathrm{CT}$ abnormalities in low-risk mTBI (GCS 15 without risk factors). The focus of mTBI treatment is the early detection of abnormal CT scans and intervention as early as possible to suppress morbidity and mortality, so abnormal CT scan has a central role in the care of mTBI patients even if the patient has a GCS score of 15 because it is related to surgery and outcome. ${ }^{6,7}$ Therefore, the authors consider that the classification of mTBI solely based on GCS cannot always be used to guarantee that mTBI patients with GCS score 15 are safe. Although there are other studies that see intracranial lesions in GCS score 15 do not affect outcomes $^{22}$, this study was only conducted on mTBI patients with GCS score 15.

The presence of focal intracranial lesions cannot always be represented by the GCS score. However, patients with a GCS score of 13 have a higher chance of having abnormal CT scans compared to patients with a GCS score of 15. Nevertheless, there are cases where patients with a GCS score of 13 do not show abnormalities on head CT scans. If we conclude that abnormal CT scans reflect serious head injury, then patients with a GCS score of 15 with intracranial lesions have a more serious injury than those with a GCS score 13 or 14 without abnormal CT scan, and vice versa. By assuming abnormal head CT scan as a sign of serious injury, observations of mTBI patients in the ward will focus more on mTBI patients with focal lesions even with GCS score 15.

This study has two endpoints, which are the need for surgery and outcome. In need for surgery, patients who present acute focal lesions on head CT scan are risk factors of undergoing surgery. In the outcome point, patients who present with acute focal lesions on the head CT scan tend to have worse outcomes than patients without acute focal lesions. These results can certainly be used as a benchmark for surgeons to be more rigorous in observing and monitoring these patients. We would like to encourage practitioner to perform head CT scan in all of mTBI patients regardless of GCS score. Patients with GCS score 15 and presence of intracranial lesion (no matter how much the volume is) have worse outcome than patients with GCS score 14 and without intracranial lesion. Presence of intracranial lesion should be the indicator of close observation in mTBI patients. In the future, we can cut hospital cost because we can determine which mTBI patients should be observed in the hospital.

\section{CONCLUSION}

In need for surgery, patients who present acute focal lesions on head CT scan are risk factors of undergoing surgery. In the outcome point, patients who present with acute focal lesions on the head CT scan tend to have worse outcomes than patients without acute focal lesions. We would like to encourage practitioner to perform head CT scan in all of TBI patients regardless of GCS score.

\section{AUTHORS CONTRIBUTION}

All authors contributed to the study conception and design. Material preparation, data collection and analysis were performed by Nyoman Golden and Putu Eka Mardhika. The first draft of the manuscript was written by Putu Eka Mardhika and all authors commented on previous versions of the manuscript. All authors read and approved the final manuscript.

\section{FUNDING}

No funding was received for this research.

\section{CONFLICT OF INTEREST}

Authors declare no conflict of interest reagrding this study.

\section{ETHICAL APPROVAL}

All procedures performed in studies invloving human participants were in accordance with ethical standards of the institutional and/or national research committee and with the 1964 Helsinki declaration and its later amendments or comparable ethical standards.

\section{REFERENCES:}

1. De Andrade AF, de Almeida AN, Bor-ShengShu E, Leurenco L, Mandel M, Marino R Jr. The value of cranial computed tomography in high-risk, mildly head-injured patients. Surg Neurol. 2006; 65 Suppl 1: S1: 10 - 1: 13. https:// doi.org/10.1016/j.surneu.2005.11.034.

2. Golden N, Niryana W, Mahadewa TGB, Maliawan S, Chandra A. Two different approaches in obtaining head computerized tomography scan in minor head injuries. $J$ Neurol Res. 2013; 3(3 - 4): 114 - 121. https:// doi.org/10.4021/jnr225w.

3. Saadat S, Ghodsi SM, Naieni KH, Firouznia K, Hosseini M, Kadkhodaie HR, Saidi H. Prediction of intracranial computed tomography findings in patients with minor head injury by using logistic regression. $J$ Neurosurg. 2009; 111(4): 688 - 694. https://doi. org/10.3171/2009.2.JNS08909.

4. Anonim. Register IRD Bedah RS Sanglah. 2012. Departemen Kesehatan RI, Denpasar.

5. Dacey RG Jr, Alves WM, Rimel RW, Winn HR, Jane JA. Neurosurgical complications after apparently minor head injury. Assessment of 
risk in a series of 610 patients. J Neurosurg. 1986; 65(2): 203 - 210. https://doi.org/10.3171/ jns.1986.65.2.0203.

6. Gomez PA, Lobato RD, Ortega JM, De La Cruz J. Mild head injury: differences in prognosis among patients with a glasgow coma scale score of 13 to 15 and analysis factors associated with abnormal CT findings. Br J Neurosurg. 1996; 10(5): $453-460$.

7. Hsiang JN, Yeung T, Yu AL, Poon WS. Highrisk mild head injury. J Neurosurg. 1997; 87(2): 234 - 238. https://doi.org/10.3171/ ins.1997.87.2.0234.

8. Miller EC, Holmes JF, Derlet RW. Utilizing clinical factors to reduce head CT scan ordering for minor head trauma patients. J Emerg Med. 1997; 15(4): 453 - 457.

9. Turedi S, Hasanbasoglu A, Gunduz A, Yandi M. Clinical decision instruments for CT scan in minor head trauma. J Emerg Med. 2008; 34(3): 253 - 9. https://doi.org/10.1016/j. jemermed.2007.05.055.

10. Saboori M, Ahmadi J, Farajzadegan Z. Indications for brain CT scan in patients with minor head injury. Clin Neurol Neurosurg. 2007; 109(5): 399 - 405. https://doi.org/10.1016/j. clineuro.2007.01.013.

11. Stiell IG, Wells GA, Vandemheen K, Clement C, Lesiuk H, Laupacis A, et al. The canadian CT head rule for patients with minor head injury. Lancet. 2001; 357(9266): 1391 - 6. https://doi. org/10.1016/s0140-6737(00)04561-x.
12. Haydel MJ, Preston CA, Mills TJ, Luber S, Blaudeau E, DeBlieux PM. Indications for computed tomography in patients with minor head injury. $N$ Engl J Med. 2000; 343(2): 100 - 105. https://doi.org/10.1056/ NEJM20007133430204.

13. Af Geijerstam JL, Oredsson S, Britton M. Medical outcome after immediate computed tomography or admisson for observation in patients with mild head injury: randomized controlled trial. BMJ. 2006; 333(7566): 465. https://doi.org/10.1136/bmj.38918.669317.4F.

14. Af Geijerstam JL, Britton M. Mild head injury: reliability of early computed tomographic findings in triage for admission. Emerg Med J. 2005; 22(2): 103 - 107. https://doi.org/10.1136/ emj.2004.015396.

15. Cullota VP, Sementilli ME, Gerold K, Watts CC. Clinicopathological heterogenity in the classification of mild head injury. Neurosurgery. 1996; 38(2): 245 - 250. https:// doi.org/10.1097/00006123-199602000-00002.

16. Stein SC, Spettell C. The head injury severity scale (HISS): a practical classification of closedhead injury. Brain Inj. 1995; 9(5): 437 - 444.

17. Teasdale G, Jennett B. Assessment of coma and impaired consciousness. A practical scale. Lancet. 1974; 2(7872): 81 - 84. https://doi. org/10.1016/s0140-6736(74)91639-0.

18. Chan KH, Mann KS, Yue CP, Fan YW, Cheung $M$. The significance of skull fracture in acute traumatic intracranial hematomas in adolescents: a prospective study. J Neurosurg. 1990; 72(2): 189 - 194.

19. Ibanez J, Arikan F, Pedraza S, Sanchez E, Poca MA, Rodriguez D, Rubio E. Reliability of clinical guidelines in the detection of patients at risk following mild head injury: results of a prospective study. J Neurosurg. 2004; 100(5): 825 - 834. https://doi.org/10.3171/ jns.2004.100.5.0825.

20. Lee YB, Kwon SJ. A more detailed classifiction of mild head injury in adult and treatment guidelines. J Korean Neurosurg Soc. 2009; 46(5): 451 - 458. https://doi.org/10.3340/ jkns.2009.46.5.451.

21. Servadei F, Teasdale G, Merry G. Defining acute mild head injury in adults: a proposal based on prognostic factors, diagnosis, and management. J Neurotrauma. 2001; 18(7): 657 - 664. https:// doi.org/10.1089/089771501750357609.

22. Lannsjo $M$, Backheden $M$, Johansson $U$, Geijerstam JL, Borg J. Does head CT scan pathology predict outcome after mild traumatic brain injury?. Eur J Neurol. 2013; 20(1): 124 - 129. https://doi.org/10.1111/j.14681331.2012.03813.x.

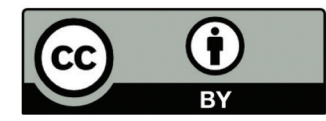

This work is licensed under a Creative Commons Attribution 